\title{
Management of comorbidities in ambulatory anesthesia: a review
}

This article was published in the following Dove Press journal:

Ambulatory Anesthesia

12 June 2015

Number of times this article has been viewed

\section{Susan Dabu-Bondoc Kirk H Shelley}

Department of Anesthesiology, School of Medicine, Yale University, New Haven, CT, USA
Correspondence: Kirk H Shelley Department of Anesthesiology, School of Medicine, Yale University, 333 Cedar Street, PO Box 20805I, New Haven, CT 06520, USA

Tel +l 2037852802

Email kirk.shelley@yale.edu

\begin{abstract}
Advances in medical science now allow people with significant medical issues to live at home. As the outpatient population ages and surgical techniques advance, the ambulatory anesthesiologist has to be prepared to handle these "walking wounded". The days of restricting ambulatory surgery procedures to American Society of Anesthesiologists class 1 and 2 patients are rapidly fading into the past. To remain competitive and economically viable, the modern ambulatory surgery center needs to expand its practice to include patients with medical comorbidities. In an environment where production and economic pressures exist, maintaining safety and good outcomes in high-risk patients for ambulatory surgery can be arduous. Adding to the complexity of this challenge is the rapid evolution of the therapeutic approaches to a variety of medical issues. For example, there has been a significant increase in the number and types of insulin a diabetic patient might be prescribed in recent years. In the case of the patient with coronary artery disease, the variety of both drug and nondrug eluding stents or new antithrombotic agents has also increased the complexity of perioperative management. Complex patients need careful, timely, and team-based preoperative evaluation by an anesthesia provider who is knowledgeable of outpatient care. Optimizing comorbidities preoperatively is a crucial initial step in minimizing risk. This paper will examine a number of common medical issues and explore their impact on managing outpatient surgical procedures.
\end{abstract}

Keywords: ambulatory surgery, medical comorbidities, diabetes, coronary artery disease, respiratory disease, obesity

\section{Introduction}

Ambulatory surgery (AS) has grown rapidly worldwide. Currently, it is the most widely practiced anesthesia subspecialty in the US; ambulatory anesthesia comprises more than $70 \%$ of all anesthetics administered nationwide. At least 50 million ambulatory procedures are performed annually, ${ }^{1}$ and in 2013, data from National Anesthesia Clinical Outcomes Registry indicate that $57 \%$ of these procedures were performed in a hospital versus a freestanding facility. ${ }^{2}$ As numerous studies confirmed the safety of ambulatory practice, a growing number of complicated surgical patients, with significant or multiple comorbidities, are utilizing the outpatient setting. More painful and invasive procedures, such as shoulder and total knee arthroplasty, mastectomy, and advanced laparoscopic surgery, which were previously considered inappropriate for $\mathrm{AS}$, are increasingly performed as day surgeries (DSs). ${ }^{3-5}$ In office-based practices, caseload has more than doubled in volume. Ophthalmic, gastrointestinal, and cosmetic procedures comprised the bulk of office-based practice, which has now extended the coverage to podiatry, gynecology, interventional radiology as well as vascular and cardiology procedures. ${ }^{6-8}$ 
Providing anesthesia for more complex and longer surgeries with sick and elderly outpatients is a challenging task for the anesthesiologist. A high level of clinical skills and sharp decision-making while managing complex patients may not only improve outcome and safety, but also decrease schedule delays and maintain efficiency. The patient's clinical status is a major consideration in preoperative evaluation. The surgeon's skills and experience, surgical environment, and anesthetic technique should all be considered as well. Appropriate resources and trained personnel must be readily available for adverse events.

\section{Safety and risk evaluation in ambulatory surgery}

Investigations evaluating risk and outcomes in AS have centered on identifying what conditions should be considered predictors of adverse events after surgery. Numerous studies indicate that in the presence of comorbidities (particularly cardiovascular and respiratory), the risk of perioperative complications after AS increases. However, evidence to support correlation between outcomes in AS and comorbidities is limited.

A recent large study, using national data from the American College of Surgeons - National Surgical Quality Improvement Program (NSQIP), reported that the incidence of morbidity and mortality within 72 hours of AS in adults $(n=244,397)$ was $0.1 \%$ or 1 in 1,053 cases. ${ }^{9}$ An earlier investigation reported a death rate per 100,000 procedures of 0.78 in AS centers and 9.2 in offices..$^{10}$ These rates confirm findings of earlier single-center studies regarding the safety of AS, reporting rates from $0.09 \%$ to $0.60 \%$ among common ambulatory procedures. ${ }^{11-13}$ High body mass index (BMI; overweight or obese), chronic obstructive pulmonary disease (COPD), hypertension (HTN), history of transient ischemic attack (TIA)/stroke, previous cardiac surgical intervention, and prolonged operative time were identified as independent risk factors for increased perioperative morbidity. ${ }^{9}$ The most common morbidities identified were unplanned postoperative intubation, pneumonia, and wound disruption. Earlier investigations ${ }^{10,14-16}$ evaluating risk factors from data using the current AS patient-selection model reported that noncompensated, poorly stabilized cardiac and respiratory patients, patients with obstructive sleep apnea (OSA), being $>85$ years of age, and preterm infants are at high-risk of complication in DS. Unplanned admissions, or return to the hospital, are more frequent after ear, nose and throat, and urology outpatient procedures. Administrative data analyses which focused on readmission outcome noted that prolonged surgical duration, cerebrovascular disease, obesity, and cardiac disease increased the risk after outpatient surgery. ${ }^{17,18}$ Whippey et a ${ }^{17}$ recently reported that surgeries lasting longer than 1 hour, high ASA (American Society of Anesthesiologists) physical status classification ( $\geq$ ASA 3), advanced age ( 80 years or older), and increased BMI were identified as predictors of unplanned hospital admission. A recent large-scale Danish study ${ }^{19}$ of a prospective cohort of 57,709 DS procedures collected from eight DS centers over a 3-year period also confirmed the safety of DS, reporting a very low rate of return hospital visits $(1.21 \%)$. The most common causes of return visits in this investigation were hemorrhage or hematoma $(0.5 \%)$, infection $(0.44 \%)$, and thromboembolic events $(0.3 \%)$. Morbidity was reported as rare, and the procedures with the highest rate of complication were tonsillectomies (11.4\%), surgically induced abortions (3.3\%), and inguinal hernia repairs $(1.23 \%)$.

\section{Patient selection in ambulatory surgery}

In the 1970s, when AS was newly introduced, simple procedures and healthy patients were eligible for AS. Only those cases that involved minimal blood loss or fluid shift, had procedure times of $<90$ minutes, used simple equipment, and entailed minimal postoperative care and pain that could be treated with oral medications were considered. ${ }^{10,20}$ Today, the only requirement to be accepted for AS is the patient's ability to go home safely on the same day of surgery. A survey ${ }^{21}$ of Canadian anesthesiologists ( $n=1,377,58 \%$ responders) indicated that more than $75 \%$ of the anesthesiologists would administer anesthesia to an ASA3 ambulatory patient, including one with stable congestive heart failure (CHF), low-grade angina pectoris (AP), asymptomatic valvular heart disease, a previous myocardial infarction (MI) older than 6 months, or one with sleep apnea without the use of narcotics. A similar proportion of the anesthesiologists considered patients with unstable angina, cardiovascular or respiratory complications, or the morbidly obese with comorbidities, as unsuitable for ambulatory procedures. If procedure and personnel were also considered, however, many AS centers would accept a patient with OSA who could receive lower-extremity regional anesthetic plus an appropriate intravenous (IV) sedation and analgesia.

Age is generally not considered a major criterion for patient selection for DS. The elderly patient can safely 
undergo outpatient surgery depending upon the complexity of the procedure and the optimization of the patient's comorbid condition. Patients with higher ASA classification but with stable comorbidities may be considered for DS. Except if severe or end stage, preoperative coexisting diseases might not be a contraindication to DS, provided there is good patient compliance to perioperative instructions and a supportive perioperative care organization. Appropriate preoperative medical therapy of comorbidity must be maintained during the perioperative period as interruption could exacerbate an otherwise stable chronic medical condition.

\section{Management of comorbidities in ambulatory anesthesia}

Conditions that were reported in association with increased risk in adult outpatients thus far include HTN, coronary artery disease (CAD), CHF, prior TIA/stroke or cardiac surgical intervention, asthma, COPD, obesity, sleep apnea, smoking, and gastroesophageal reflux..$^{917,22-26}$ Overall, the most encountered adverse events were cardiovascular - in cardiac patients; or postoperative respiratory - in asthmatic, morbidly obese, and sleep apnea patients. ${ }^{10}$ Recognition and optimization of comorbid medical conditions in advance of the day of surgery is crucial because it enables implementation of perioperative preventative measures that minimize adverse events. Prevention of postoperative exacerbation of chronic disease is important and requires expertise to achieve a good outcome.

\section{Hypertension and cardiovascular disease}

Cardiovascular comorbidities such as HTN, ischemic heart disease (IHD), arrhythmia, and CHF are common among the DS population. CAD, valvular disease (particularly aortic), and $\mathrm{CHF}$ are considered the most challenging.

Approximately $30 \%$ of patients who undergo surgery annually in the US have IHD. Data remain limited in terms of risk of cardiac events in AS. Surgical risk in cardiac patients has been largely evaluated in terms of the type of surgery. Currently, most outpatient procedures, including laparoscopic surgery, are now considered low-risk $(<1 \%$ cardiac events). ${ }^{10}$ Although the general mortality rate from CAD (acute MI) remains significant, early therapeutic interventions such as angioplasty, thrombolysis, aspirin, heparin, and statin therapy have led to the steady decline of mortality rates from MI. ${ }^{27,28}$ Hence, patients with IHD are now at much lesser risk of perioperative adverse events after surgery than in the past. Aggressive reperfusion therapy for patients with IHD lowers mortality rate threefold to $6.5 \%$, from a $15 \%$ to $20 \%$ mortality rate, compared to patients who do not receive reperfusion therapy.

\section{Hypertension}

In the patient with HTN, the goals of preoperative evaluation include assessment of 1) adequacy of control of blood pressure (BP), 2) whether the antihypertensive treatment is effective, and 3) the presence of target-organ damage. ${ }^{29}$ To date, evidence is lacking to demonstrate that the incidence of postoperative complications is increased when hypertensive patients undergo elective surgery; however, in the presence of end-organ damage, HTN does increase the risk of surgery. ${ }^{30,31}$ AS patients, like inpatients, should continue to take $\beta$-blockers and calcium channel blockers (CCBs), but not angiotensin-converting enzyme (ACE) inhibitors, on the day of surgery. ${ }^{32}$ Studies have shown that patients who are on long-term treatment, with ACE inhibitors and angiotensin receptor blockers, experience hypotension that requires vasopressor treatment more often after induction of anesthesia, than those in whom such medications have been withheld on the day of surgery. ${ }^{33-35}$ Withdrawal of hypertensive medications during the preoperative period may result in rebound HTN that may require immediate treatment. Although the presence of labile BP during the perioperative period has been shown to increase the risk of stroke, acute kidney injury (AKI), and 30-day mortality in patients undergoing cardiac surgery, ${ }^{36}$ evidence is limited in the ambulatory patient population.

During anesthesia, the goal is to prevent extreme swings in BP, as hypertensive patients are known to exhibit exaggerated BP response to anesthetic drugs. Regardless of preoperative treatment of BP to normotensive levels, direct laryngoscopy and tracheal intubation may still result in substantial increase in $\mathrm{BP}^{37}$ The anesthetic is designed to blunt hypertensive responses during anesthesia, and the patient is monitored to detect myocardial ischemia. Postoperatively, monitoring of end-organ function is continued, and periods of BP elevation must be anticipated.

Patients with pulmonary HTN (mean pulmonary artery pressure of $>25 \mathrm{~mm} \mathrm{Hg}$ at rest or $>30 \mathrm{~mm} \mathrm{Hg}$ with exercise) should continue all long-term pulmonary vasodilator therapies throughout the perioperative period. ${ }^{38}$ Pulmonary vasodilator medications currently used for pulmonary HTN include CCBs, prostacyclins, nitric oxide, endothelin 
receptor blockers, and phosphodiesterase inhibitors. ${ }^{39}$ Patients with pulmonary HTN are at increased risk of right heart failure and sudden death during the perioperative period. $^{40}$

\section{Coronary artery disease or ischemic heart disease}

Surgical patients with CAD or IHD need optimization to have a good postoperative outcome. The overall goal of treatment of chronic stable angina is to achieve complete or almost complete elimination of angina chest pain and to return to normal activities with minimal side effects. ${ }^{41}$ Being cognizant of conditions that may exacerbate or worsen an otherwise stable angina, such as fever, infection, tachycardia, anemia, heart failure, thyrotoxicosis, or cocaine use, is helpful in identifying surgical patients with CAD who may have an exacerbation of their chronic disease. In the presence of IHD, HTN increases the risk of coronary events as a result of increased myocardial oxygen demand, left ventricular hypertrophy, and direct vascular injury. ${ }^{42}$ Treatment of HTN to normotensive levels decreases the risk of stroke, MI, and heart failure. $\beta$-Blockers and $\mathrm{CCBs}$, in addition to lifestyle modifications, are used in the treatment of HTN in patients with AP. ${ }^{43}$ When HTN is accompanied by ventricular dysfunction, the use of an ACE inhibitor or angiotensin receptor blocker is recommended. Hypotension in the context of IHD is typically caused by presence of left or right ventricular dysfunction or cardiac dysrhythmias.

Medications that are currently used in the treatment of HTN in patients with AP include nitrates, $\beta$-blockers, CCBs, and antiplatelet drugs (APDs). $\beta$-Blockers are known to be more effective than CCBs in reducing the incidence of MI. ${ }^{44}$ Perioperative use of $\beta$-blockers is recommended by the American Heart Association and the American College of Cardiology in patients already on $\beta$-blockers or in highrisk patients undergoing noncardiac procedure to decrease the risk of MI or myocardial ischemia. ${ }^{45,46}$ Because of the risk of stroke, severe bradycardia, or severe hypotension, $\beta$-blockers should be used with caution in patients not previously treated with $\beta$-blockers or in patients undergoing intermediate- or low-risk noncardiac surgery. Abrupt withdrawal of $\beta$-blockers after prolonged administration can worsen ischemia in patients with stable chronic angina. CCBs decrease smooth muscle tone, dilate coronary arteries, decrease myocardial contractility and oxygen consumption, and decrease systemic BP. Various CCBs such as amlodipine, nicardipine, felodipine, isradipine, and long-acting nifedipine are potent vasodilators and are effective in treating both HTN and angina. Unlike short-acting $\mathrm{CCBs}$, such as verapamil and diltiazem, long-acting $\mathrm{CCBs}$ are comparable to $\beta$-blockers in relieving angina pain and are uniquely effective in decreasing the frequency and severity of Prinzmetal variant (vasospastic) angina. $\mathrm{CCBs}$ are contraindicated in patients with severe $\mathrm{CHF}$ or severe aortic stenosis.

Diet and statin therapy are used to lower cholesterol greater than $130 \mathrm{mg} / \mathrm{dL}$. The use of statins to lower cholesterol, particularly low-density lipoprotein (LDL) is associated with a significant decrease in the risk of death resulting from cardiac events. ${ }^{41}$ The goal is to decrease levels of LDL to less than $100 \mathrm{mg} / \mathrm{dL}$, and there is a known additional benefit in lowering LDL further, to less than $70 \mathrm{mg} / \mathrm{dL}$, in patients with IHD. ${ }^{28}$

Antiplatelet therapy is important in the management of IHD. Acute coronary syndrome is a hypercoagulable state, resulting from focal disruption of an atheromatous plaque that triggers a coagulation cascade, leading to a thrombus formation that occludes the coronary artery. The formation and presence of "vulnerable plaques" in CAD, which are most likely to rupture and form an occlusive thrombus, predicts a greater risk of MI regardless of the degree of coronary artery stenosis. It is important to know that acute MI is most often caused by rupture of plaque in a partly stenosed coronary artery with less than $50 \%$ blockage.

Currently, three classes of APDs are commonly used in the management of IHD: aspirin, thienopyridines (clopidogrel and prasugrel), and platelet glycoprotein IIb/IIIa inhibitors (eptifibatide, tirofiban, and abciximab). A fourth class that affects platelet cAMP (dipyridamole) is currently not widely used.

Preoperative evaluation concentrates on clinical course, patient functional status, and surgery involvement. Stability of angina in patients with IHD must be assessed (eg, any change of frequency and duration of angina pain from their baseline, exertion or exercise capacity prior to pain onset, medications to relieve pain, and other associated symptoms). If instability is suspected or if recent symptom changes, such as alteration in workload that induces chest pain is present, refer patient for cardiac evaluation or defer surgery as inpatient, as appropriate. In patients who had a recent MI, it is currently assumed to wait at least 30 days after MI prior to DS, provided the patient's functional status is adequate and angina symptoms have resolved. ${ }^{42}$

There is a paucity of evidence regarding which anesthesia technique is most beneficial in cardiac patients. Regardless, the fundamental goals of anesthetic management include avoiding hypotension, bradycardia, and factors that increase 
myocardial oxygen consumption such as HTN, tachycardia, pain, or stress; preventing hypoxia; and maintaining coronary perfusion.

Early diagnosis and prompt treatment of perioperative MI reduces morbidity and mortality. ${ }^{44,47}$ Anesthesia providers are in a unique position to facilitate prompt diagnosis and initial treatment of perioperative ischemia.

Troponin (T or I) is a cardiac-specific (protein) biochemical marker for acute MI. Its circulating level increases early in MI, typically within 3 hours after myocardial injury, and remains elevated for 7-10 days. Troponin is more specific than CK-MB for detecting MI. Elevated troponin levels and ECG are known powerful predictors of adverse cardiac events in patients with angina pain. The degree of elevation of the biomarker from normal reference range defines the presence of and parallels the magnitude of the infarction. Chest pain that emerges during the perioperative period is of particular concern. Almost two-thirds of patients who develop a perioperative MI describe either 1) a new-onset angina pain, 2) a change in their angina pattern, or 3) a more severe-thanbaseline angina pain. In many ways, the surgical procedure may be viewed as a stress test that either the patient passes or fails. If they fail it (ie, cardiac instability, intraoperative or postop angina), admission overnight should be seriously considered.

\section{Acute management of heart disease exacerbations}

In patients suspected of having ischemia or MI during the perioperative period, initial steps of management include oxygen administration, evaluation of hemodynamic stability, and obtaining a 12-lead ECG. Pain relief, with IV morphine and/or sublingual nitroglycerin, is important to reduce catecholamine release and consequent increase in myocardial oxygen requirements. $\beta$-Blockers are administered early to relieve ischemic chest pain, reduce infarct size (by reducing heart rate, BP, and myocardial contractility), and prevent life-threatening dysrhythmias. ${ }^{43}$ However, $\beta$-blockers should not be used if a patient is unstable hemodynamically, in heart failure, low cardiac output state, heart block, or if at risk of cardiogenic shock. ${ }^{46}$ Administration of $\beta$-blockers is associated with a significant decrease in early (inhospital) and long-term mortality and MI. ${ }^{43,46}$ Aspirin (clopidogrel or prasugrel, if intolerant to aspirin) is administered to reduce further thrombus formation in the coronary artery. If urgent surgical intervention is likely, use of platelet glycoprotein $\mathrm{IIb} / \mathrm{IIIa}$ inhibitor is recommended. It is critical to reestablish blood flow in the obstructed coronary artery as soon as possible because time to reperfusion strongly influences the outcome of acute MI. ${ }^{44}$ Reperfusion can be achieved with pharmacologic thrombolysis or coronary angioplasty, with or without placement of intracoronary stent.

In the absence of ventricular dysrhythmias, prophylactic administration of lidocaine or antidysrhythmic drugs is not recommended. CCBs should not be administered routinely but be reserved for patients with persistent myocardial ischemia despite optimal use of aspirin, $\beta$-blockers, nitrates, and heparin. Routine administration of magnesium is also not recommended but is indicated in patients with torsades de pointes ventricular tachycardia.

Thrombolytic therapy (TT) with streptokinase, tissue plasminogen activator, reteplase, or tenecteplase, is administered within 30-60 minutes of hospital arrival (if patient, not hospital based), or within 12 hours of symptom onset. Clot dissolution restores normal antegrade blood flow in the occluded artery. Thrombolysis is more difficult to achieve if delayed. Intracranial hemorrhage is the most feared complication of TT and is more likely to occur in the elderly (>75 years), in individuals with uncontrolled HTN, recent surgery, or recent gastrointestinal bleeding. TT is not indicated in unstable angina or non-ST elevation MI and has been shown to increase mortality in these cases.

When feasible, angioplasty or percutaneous coronary intervention (PCI) is a preferred procedure in the treatment of an ischemic process. It must be performed within 90 minutes of hospital arrival and within 12 hours of onset. It is the treatment of choice in patients with severe heart failure, pulmonary edema, or if TT is contraindicated. About $5 \%$ of patients who undergo immediate PCI require emergency cardiac surgery due to anatomic reasons or technique failure. Coronary stent placement, in combination with use of APDs during emergency PCI, allows a maximum chance of achieving normal antegrade coronary blood flow and may reduce the likelihood of a subsequent revascularization procedure. Emergency coronary artery bypass grafting is normally reserved for patients who failed angioplasty and those with infarction-related ventricular septal rupture or mitral regurgitation.

$\mathrm{CHF}$ has been shown to be one of the independent predictors of adverse cardiac events after surgery. ${ }^{48}$ Subsequently, $\mathrm{CHF}$ has been regarded as more of a risk ${ }^{49}$ factor for adverse cardiac events than CAD. Patients with S3 gallop would have an 11 point score, the highest value assigned to any risk factor using the Multifactorial Risk Index by Goldman et al. ${ }^{50}$

The valvular disorder aortic stenosis is the most predictive comorbidity of perioperative adverse events, particularly 
when symptoms (angina, CHF) appear. Symptomatic patients necessitate cardiac evaluation and aggressive perioperative management, but administering anesthesia in the outpatient setting is strongly discouraged. Heart transplant patients may present to AS as they develop ${ }^{51}$ biliary disorder requiring laparoscopic cholecystectomy. Their clinical course may be complicated by the lack of heart rate-mediated adjustments to their cardiac output. It is advisable to assure the availability of an external pacemaker or isoprenaline (Isuprel, Hospira, Lake Forest, IL, USA) before proceeding with their surgery.

\section{Anticoagulation and other perioperative issues in the cardiac patient}

Because of increased risk of bleeding or thrombosis during the 1 st month after coronary stent insertion, a minimum of 30 days is advised prior to outpatient surgery. Patients with coronary stents undergoing noncardiac surgery are at risk for stent thrombosis and a major cardiovascular event with interruption of dual antiplatelet (aspirin and clopidogrel) therapy. ${ }^{52}$ Bridging with low molecular-weight (LMW) heparins may poorly protect against adverse cardiovascular events. ${ }^{53}$ In situations where clopidogrel therapy needs to be temporarily discontinued because of risk of bleeding, continuation of aspirin is strongly recommended to decrease the chance of thrombosis. Maintaining APD therapy throughout the operative period appears generally safe in many outpatient procedures and should be maintained in all situations in which the risk of surgical hemorrhage is low. The next major risk factor for stent thrombosis is the time interval between stent placement and the intended surgery. This time interval is inversely related to the risk of thrombotic complication, with the highest mortality rate occurring less than a month after stent placement. For patients with the drug-eluting type of stent, it is recommended that elective surgery be delayed for at least a year, and a minimum of 6 weeks for patients with bare-metal stents. Vigilant perioperative monitoring is the key for prompt recognition of myocardial ischemia and/or infarction due to thrombosis, to initiate rapid triage for PCI procedure for coronary occlusion intervention. One must be very cautious with the use of neuraxial anesthetic because of the risk of epidural hematoma.

Withholding anticoagulation places patients with mechanical heart valves or atrial fibrillation at risk $(\sim 5 \%-8 \%$ risk) of arteriovenous thromboembolism as a result of a rebound hypercoagulable state and prothrombotic effects of surgery. In patients who are scheduled for minor surgery, in which blood loss is expected to be minimal, anticoagulation may be continued. In major surgery, warfarin is typically discontinued 3-5 days preoperatively, with IV unfractionated heparin or subcutaneous (subQ) LMW heparin begun and continued until the day before or the day of surgery. Postoperatively, heparin is resumed when the risk of bleeding has lessened. Elective surgery should be avoided when possible in the first month after an acute episode of arterial or venous thromboembolism.

In parturients with prosthetic valves, anticoagulation therapy is particularly important because the incidence of arterial embolization is greatly increased during pregnancy. Unfortunately, warfarin administration during the first trimester can be associated with fetal defects and fetal death. Hence, warfarin is discontinued during pregnancy, and subQ standard or low-dose LMW heparin is administered until delivery. Low-dose aspirin can be used in conjunction with heparin therapy as it is safe for the mother and fetus.

Patients with an implantable cardiac defibrillator scheduled for surgical procedures may be performed as an outpatient, with a preference by many providers to use an integrated facility (AS center within a hospital) versus office-based or free-standing facility. Over the years, caring for a patient with an implantable cardiac defibrillator has become easier with a growing consensus among device manufacturers regarding device capabilities and settings. This is especially important regarding the effect of magnets when used to deactivate the defibrillator component, which has in the past varied greatly among manufacturers. It can be quite helpful to have the input from the patient's cardiologist and the device manufacturer regarding these issues.

\section{Respiratory disease}

Asthma and COPD have been shown by several studies to be associated with increased complications perioperatively, ${ }^{54-56}$ but data are scant in the AS population.

Airway responsiveness remains a major concern in the perioperative management of patients with bronchial asthma and COPD. An evidence-based approach to perioperative care is desirable to guide management of respiratory disorders. To date, perioperative management and optimization $^{57,58}$ strategies include: 1) adequate control of airway hyperreactivity and respiratory infection, 2) aggressive use of $\beta_{2}$-adrenergic agonists (or leukotriene antagonists) ${ }^{59}$ and systemic administration of steroids for the treatment of exacerbation, 3) smoking cessation, and 4) evidence-based anesthetic technique, including intra- and postoperative use of oxygen and selective use of volatile agents. 
Ambulatory patients with COPD must be carefully evaluated to assess the reversible component of disease. The use of preoperative pulmonary function testing with and without bronchodilators ${ }^{60}$ is widely used in severe COPD to determine the reversibility of obstruction. A marked decrease in $\mathrm{FEV}_{1}$ (forced expiratory volume in 1 second) $(<0.75$ of vital capacity) was demonstrated to be a predictor of respiratory complications and mortality, ${ }^{54}$ but other spirometry results ${ }^{61}$ were not. Hypercapnia and hypoxemia of the arterial blood gas have been shown to be useful in predicting increased perioperative risk. All reversible components including bronchospasm, infection, secretion, and atelectasis should be treated with bronchodilators, antibiotics, and pulmonary therapy prior to surgery.

Stopping smoking is strongly encouraged because it has been shown to reduce the risk of perioperative complications. ${ }^{62}$ A randomized controlled study by Lindstrom et $\mathrm{al}^{63}$ demonstrated that smoking cessation intervention with discontinuation of smoking 4 weeks prior to surgery in general and orthopedic cases could be an effective tool to reduce postoperative complication. Prior recommendations had varied from 2 weeks prior to surgery to $6-8$ weeks prior to surgery, to allow the ciliary epithelium to recover normal function and decrease mucus production during anesthesia. Interestingly, it has been shown that undergoing surgery is associated with an increased likelihood of smoking cessation in the older US population; however, it is more likely in association with major surgery than with outpatient surgery ${ }^{64}$ Regardless of the presence of smoking in patients with a reversible component of airway hyperresponsiveness and/or obstructive disease, a 48-hour course of systemic corticosteroid and $\beta_{2}$-adrenergic agonist is recommended. ${ }^{65}$ Furthermore, short-term administration of steroids has not been found to have an adverse effect on wound healing or infection control. ${ }^{66-68}$

In the presence of bronchial hyperreactivity, significant bronchospasm caused by airway instrumentation remains a major anesthetic concern. Preoperative treatment with an inhaled $\beta_{2}$-sympathomimetic, in combination with systemic corticosteroids, has been demonstrated to be more effective than pretreatment with inhaled $\beta_{2}$-agonist alone. Silvanus et $\mathrm{al}^{65}$ showed that preoperative treatment with combined corticosteroid and salbutamol minimizes intubation-evoked bronchoconstriction much more effectively than pretreatment with inhaled $\beta_{2}$-sympathomimetic salbutamol alone. In the same study, pretreatment with either salbutamol alone or salbutamol-methylprednisolone combination significantly and similarly improves lung function within a day. However, only the combined regimen decreases the incidence of wheezing after tracheal intubation.

The use of laryngeal mask airway for general anesthesia has less laryngeal stimulation than tracheal intubation, thus lowering the risk of bronchospasm. Drugs causing histamine release are avoided. If appropriate, use of regional anesthesia is preferred. One should exercise caution with supraclavicular or interscalene blocks because a pneumothorax could have dramatic effects in the presence of COPD or asthma.

Another major concern for surgical patients is postoperative reintubation after planned extubation (RAP) following general anesthesia. A recent retrospective study ${ }^{69}$ of a cohort of $>220,000$ patients (recorded from a quality assurance database) who underwent endotracheal intubation for general anesthesia indicated that $0.06 \%$ sustained postoperative RAP. Risk factors identified for RAP include COPD, pneumonia, systemic inflammatory response, and airway surgery. From the data, a RAP index was created taking into account higher ASA classification, conscious disturbance, COPD, pneumonia, systemic inflammatory response, room air $\mathrm{SpO}_{2}<95 \%$, hypothermia, airway surgery, and head and neck surgery. The RAP index was shown to have a high predictive value (receiver operating characteristic curve $=0.873$ ) regarding the likelihood that a patient would require reintubation.

\section{Hepatic disease}

Data indicate that the elderly patient with cirrhosis undergoing major surgery is at higher risk of death for up to 90 days postoperatively; ${ }^{70}$ however, there is a paucity of research in this regard in AS patients. In an investigation evaluating operative mortality risk in patients with cirrhosis undergoing orthopedic, major digestive, and cardiovascular procedures, Teh et $\mathrm{al}^{70}$ indicated that factors such as MELD (model for end-stage liver disease) score, age, and ASA class can quantify the risk of mortality postoperatively in patients with cirrhosis and can guide decision making as to whether elective surgical procedures should be delayed until after liver transplantation. In this study, the 30-day mortality ranged from $5.7 \%$ (MELD score $<8$ ) to more than 50\% (MELD score $>20)$.

\section{Renal impairment}

Preventing acute renal failure in the postoperative period is an important consideration in perioperative management, particularly in the elderly and those with preexisting renal insufficiency (RI), diabetes, and long-standing HTN. .1,72 $^{7}$ In these patients, optimization strategies include BP control, avoidance of fasting-induced hypovolemia, ${ }^{73}$ glucose 
monitoring, and estimation of creatinine clearance. ${ }^{74}$ Using a large national clinical data set (American College of Surgeons - NSQIP) of general surgery procedures performed in 121 US medical centers, Kheterpal et $\mathrm{al}^{72}$ determined the incidence, risk factors, and mortality impact of AKI after general surgery. The investigators identified eleven independent preoperative predictors of postoperative AKI, namely, age 56 years or older, male sex, HTN, diabetes mellitus (DM) necessitating oral therapy, DM necessitating insulin therapy, active $\mathrm{CHF}$, ascites, mild preoperative RI, moderate preoperative RI, emergency surgery, and intraperitoneal surgery. From this data set, the complication rate for AKI was $1.0 \%$, but increases to $9 \%$ with the presence of the above listed risk factors.

\section{Diabetes mellitus}

$\mathrm{DM}$ is one of the five leading causes of premature death worldwide. With a prevalence that has been rapidly increasing, more than 300 million people have diabetes across the globe. ${ }^{75}$ In the US, it was the seventh leading cause of death in 2010. About 29 million Americans have diabetes, with an estimated incidence in the US of $9.3 \%$ in $2012^{76}(4 \%-5 \%$ in UK), an incidence that has nearly doubled since the mid1970s. Approximately 90\% of DM patients are non-insulin dependent, and most are elderly and overweight.

Complications and comorbid conditions associated with DM include, but are not limited to, hypoglycemia, HTN, dyslipidemia, cardiovascular disease, heart attack, stroke, blindness and eye problems, kidney disease, and amputations. Regardless of medical specialty, DM is known to be associated with increased inhospital morbidity and increased duration of hospital stay. ${ }^{75,77}$ Multiple studies have shown that diabetic patients undergoing major surgery, cardiac or noncardiac, are at increased risk of mortality and morbidity. ${ }^{78-80}$

Although patients with DM often have one or more comorbidities, DM is not a contraindication to outpatient surgery. A consensus statement on perioperative blood glucose management published by the Society of Ambulatory Anesthesia (SAMBA, USA), as well as by the National Health Services (NHS) Diabetes in the UK, ${ }^{81}$ provides guidelines to help improve perioperative care of ambulatory patients with diabetes. ${ }^{82}$ Consensus outlines a conceptual model of care for all diabetic patients undergoing elective surgery, beginning at the primary care referral to preoperative assessment, admission, through recovery, postoperative care, and discharge. The model was criticized for its limitations, including the consideration that urgent and emergency procedures have been increasing in many hospitals. ${ }^{75}$ It is important to note that the recommendations from both guidelines are largely based on expert opinion, as there is limited evidence due to lack of supporting studies.

Preoperative evaluation of DM patients includes assessment of their fasting blood glucose level and optimizing their treatment using either hypoglycemic medications and/or parenteral insulin. When glucose concentrations are significantly elevated, IV or subQ insulin is utilized. ${ }^{83}$ The ambulatory surgical facility must have the necessary equipment to monitor blood glucose levels. The importance of frequent postoperative assessment of blood glucose levels in reducing infectious complications has been previously demonstrated. ${ }^{84}$

Areas of clinical controversy in managing surgical patients with diabetes have been addressed. ${ }^{75}$ These include ideal blood glucose range (and measurement error), utility of preoperative glycated hemoglobin $\left(\mathrm{HbA}_{1 \mathrm{c}}\right)$, preoperative dose of long-acting insulin, and perioperative use of metformin. Literature on the use of dexamethasone, ${ }^{85}$ as well as the choice of IV fluid in the diabetic patient, ${ }^{86}$ has recently been published.

The American Association of Clinical Endocrinologists with the American Diabetes Association Consensus Statement ${ }^{87}$ is nearly in conformity with the NHS guidelines regarding the ideal inhospital glucose range for noncritically ill DM patients: $6-10 \mathrm{mmol} / \mathrm{L}$ (in the US, the lower limit is $5.6 \mathrm{mmol} / \mathrm{L}$ or $100 \mathrm{mg} / \mathrm{dL}$ ). There is substantial evidence that good glycemic control decreases perioperative infection, morbidity, and mortality. ${ }^{79,80}$ According to the NHS guidelines, a range of $4-12 \mathrm{mmol} / \mathrm{L}(70-215 \mathrm{mg} / \mathrm{dL})$ is also acceptable. Some experts argue against the use of this extended range. In vitro data demonstrate that the upper limit of $12 \mathrm{mmol} / \mathrm{L}(215 \mathrm{mg} / \mathrm{dL})$ results in a constellation of changes in endothelial function, impaired neutrophil function, decreased complement activity, expression of adhesion molecules, and enhanced cytokine synthesis, all of which facilitate inflammation exacerbation and thereby increase infection. ${ }^{88}$ Likewise, experts argue against the lower limit of $4 \mathrm{mmol} / \mathrm{L}(70 \mathrm{mg} / \mathrm{dL})$ as it is close to glucose values that may induce hypoglycemia in some DM patients. Health care providers are reminded that although published guidelines can help in clinical decision-making and maintaining a high standard of care, guidelines should not be regarded as rigid algorithms that should be followed blindly.

It has been suggested that preoperative $\mathrm{HbA}_{1 \mathrm{c}}$ values be determined not only in DM patients undergoing major surgery but also in all elective surgical patients with DM. 
This approach was proposed not only to influence the timing of elective surgery but also to help identify surgical patients with undiagnosed DM as well. There is evidence to show that delaying major surgery until glycemic control is improved helps decrease serious morbidity and mortality.

Current data indicate that there is a relationship between good preoperative glycemic control, as determined by $\mathrm{HbA}_{1 \mathrm{c}}$ concentrations, and reduced incidence of systemic and surgical complications, lower mortality, and shorter hospital stay. In addition, the association between inadequate preoperative glucose control and adverse outcomes has also been demonstrated in several surgical specialties such as cardiac, ${ }^{89}$ vascular, ${ }^{90}$ colorectal,${ }^{91}$ orthopedics, ${ }^{92}$ and neurosurgery. ${ }^{93} \mathrm{HbA}_{1 \mathrm{c}}$ values $>8.6 \%(70 \mathrm{mmol} / \mathrm{L})$ were associated with a fourfold increase in mortality after cardiac surgery. ${ }^{89}$

The utility of $\mathrm{HbA}_{1 \mathrm{c}}$ was recently highlighted by its integration into the guidelines for the diagnosis of DM in the $\mathrm{UK},{ }^{94}$ following the recommendations of the world health organization. $\mathrm{A} \mathrm{HbA}_{1 \mathrm{c}}$ value of $>6.5 \%(48 \mathrm{mmol} / \mathrm{L})$ on repeated testing was defined as being a diagnostic of DM, and values ranging between $6.0 \%$ and $6.4 \%(42-47$ $\mathrm{mmol} / \mathrm{L}$ ) as an indication of high risk for DM, and values in the range $4.0 \%-6.0 \%(20-42 \mathrm{mmol} / \mathrm{L})$ to be in the diabetic range. Additionally, $\mathrm{HbA}_{1 \mathrm{c}}$ concentrations of $6.5 \%-7.5 \%$ (48-58 $\mathrm{mmol} / \mathrm{L})$ were considered as the target for diabetic patients, with the higher levels accepted for patients at risk for hypoglycemia.

Opinions regarding the optimal dose of perioperative long-acting insulin vary. As basal insulin preparations were introduced, insulin therapy has changed in many diabetic patients. ${ }^{75}$ The use of long-acting insulin in combination with short-acting analogs has enabled type $1 \mathrm{DM}$ patients to attempt to simulate the nondiabetic state by controlling both basal and postprandial insulin needs. Type 2 diabetic patients who have difficulty controlling their glucose level increasingly use long-acting insulin formulations.

The NHS guidelines recommend that the usual dose of long-acting insulin be used prior to surgery regardless of whether there is a short or long interval of fasting. ${ }^{81}$ A similar recommendation was provided by SAMBA guidelines for AS. ${ }^{82}$ Both NHS and SAMBA guidelines assume that the dose of long-acting insulin may need to be decreased in patients who experience a significant drop in overnight glucose values, those who miss meals, or those who snack in addition to regular meals. NHS suggests that the usual dose of long-acting insulin be decreased by a third in such patients. One must be mindful that the evidence was very limited at the time of the proposal by NHS. A recent study ${ }^{95}$ investigated 400 type 1 and 2 diabetic patients undergoing elective noncardiac procedures to identify which dose $(80 \%$ of usual dose, dose provided by primary physician, or a simple dose derived locally) of insulin glargine is appropriate before surgery. No significant differences were found among the three groups in the number of patients achieving glucose levels between 5.5 and $9.9 \mathrm{mmol} / \mathrm{L}$ regardless of whether glargine was used alone or in combination with bolus insulin. In addition, similar glucose levels were achieved despite notable differences in the preoperative dose used by each group (80\%, 64\%, 54\%, respectively). Hypo- or hyperglycemia was uncommon. Investigators of this study suggested that, despite the need for further research on this matter, using $80 \%$ of the usual evening dose of insulin is a safe, simple, and effective approach.

\section{Morbid obesity and obstructive sleep apnea}

Morbidly obese patients (BMI $>40 \mathrm{~kg} / \mathrm{m}^{2}$ ) with optimized comorbid conditions could safely undergo AS, but not those who are super obese $\left(\mathrm{BMI}>50 \mathrm{~kg} / \mathrm{m}^{2}\right)$. Previous studies have identified obesity and OSA as risk factors for perioperative complications. However, other studies ${ }^{96-100}$ have indicated that neither obesity nor OSA influences perioperative complications or unplanned admission after AS. The rates of postoperative HTN, hypotension, hypoxia, cancelation of surgery, delayed discharge, and unplanned hospital admission after DS in the morbidly obese were shown not to differ from that of the nonobese. ${ }^{100}$ From this data, although the outpatient morbidly obese patients were noted to be younger, they had more comorbidities than their nonobese counterparts. Lastly, a recent evaluation of 1,487 patients with incident heart failure ${ }^{101}$ reported that being overweight (BMI 25 to $<30 \mathrm{~kg} / \mathrm{m}^{2}$ ) or obese (BMI $\geq 30 \mathrm{~kg} / \mathrm{m}^{2}$ ) appears to have a protective association with survival and lower mortality after the development of heart failure.

Approximately $60 \%-70 \%$ of morbidly obese patients have sleep-disordered breathing such as OSA and obesityrelated hypoventilation syndrome. OSA is a sleep disorder that entails frequent episodes of partial or complete upper airway collapse during sleep. Recognized as an important cause of morbidity and mortality, some studies have shown that it is also an independent risk factor for HTN, cardiovascular disease, and stroke. ${ }^{102}$ Patients affected by OSA are more prone to perioperative complications such as HTN, dysrhythmia, desaturation, airway obstruction, or 
reintubation. ${ }^{103}$ Sedative and opioid drugs may exacerbate sleep-related apneic episodes. Regional anesthesia is an alternative when appropriate, to circumvent difficulties in airway control and potentially lessen the respiratory effects of general anesthesia.

OSA is often undiagnosed or underestimated. Patients with OSA are mainly categorized into: 1) documented OSA with use of continuous positive airway pressure (CPAP) or other devices at home, 2) mild OSA not requiring CPAP, and 3) undiagnosed - not been evaluated by polysomnography. Polysomnography assigns an apneic/ hypopneic index (AHI) number indicating the degree of severity of OSA: mild (AHI $=5-15)$, moderate (AHI =16-30), or severe OSA (AHI >30). ${ }^{104}$ Most ambulatory centers accept patients with suspected OSA without prior polysomnography studies.

Data support that OSA patients are at high risk for severe, and even fatal, postoperative complications if not adequately monitored and managed, ${ }^{105,106}$ but no evidence exists regarding the relationship of severity of OSA to the risk of complications. OSA patients with inadequately treated comorbid conditions should not be operated in an outpatient setting. ${ }^{99}$ An algorithm for evaluating and preparing patients with OSA for AS has been published. ${ }^{107}$

Diagnosed OSA patients who use CPAP machines and are able to use their CPAP device in the postoperative period may be considered for outpatient procedure if their comorbid medical conditions are optimized. Patients with a presumed diagnosis of OSA (ie, based on screening tools such as STOP-BANG [snoring, tiredness during day time, observed apnea, high BP, BMI, age, neck circumference, gender] questionnaire) may be considered for outpatient surgery if their comorbid conditions are optimized and if their postoperative pain relief can be provided predominantly by nonopioid analgesic techniques. Patients who will likely require opioids for pain after discharge should be able and willing to use CPAP postoperatively. For OSA patients undergoing upper airway procedures, there is no recommended guideline as evidence is limited, ${ }^{99}$ and clinical decision should be made on an individualized basis.

\section{Summary}

The "sick" outpatient can represent a significant challenge to a busy AS center. The most common comorbidities include HTN, diabetes, CAD, pulmonary dysfunction (COPD and OSA), and obesity. This article has reviewed some of the preoperative evaluation, intraoperative management, and postoperative follow-up that may be required. While this population may represent a significant challenge, it has been our experience that they also can be among the most rewarding to care for.

\section{Disclosure}

The authors report no conflicts of interest in this work.

\section{References}

1. Cullen KA, Hall MJ, Golosinskiy A. Ambulatory surgery in the United States, 2006. Natl Health Stat Report. 2009;11:1-25.

2. Cutter TW. The subspecialty of ambulatory anesthesia. Am Soc Anesthesiologists Newsl. 2014;78(9):10-13.

3. Lovald S, Ong K, Lau E, Joshi G, Kurtz S, Malkani A. Patient selection in outpatient and short-stay total knee arthroplasty. J Surg Orthop Adv. 2014;23(1):2-8.

4. Case C, Johantgen M, Steiner C. Outpatient mastectomy: clinical, payer, and geographic influences. Health Serv Res. 2001;36(5):869-884.

5. Gagne JP, Al-Obeed O, Tadros S, Moonje V, Yelle JD, Poulin EC. Advanced laparoscopic surgery in a free-standing ambulatory setting: lessons from the first 50 cases. Surg Innov. 2007;14(1):12-17.

6. Kurrek MM, Twersky RS. Office-based anesthesia. Can J Anaesth. 2010;57(3):256-272.

7. Koenig L, Doherty J, Dreyfus J, Xanthopoulos J. An Analysis of Recent Growth of Ambulatory Centers. Rockville, MD: KNG Health Consulting; 2009.

8. Osman B, Shapiro FE. Safe anesthesia in the office-based surgical setting. Am Soc Anesthesioogists Newsl. 2014;78(9):14-17.

9. Mathis MR, Naughton NN, Shanks AM, et al. Patient selection for day case-eligible surgery: identifying those at high risk for major complications. Anesthesiology. 2013;119(6):1310-1321.

10. Bettelli G. High risk patients in day surgery. Minerva Anestesiol. 2009; 75(5):259-268.

11. Warner MA, Shields SE, Chute CG. Major morbidity and mortality within 1 month of ambulatory surgery and anesthesia. JAMA. 1993; 270(12):1437-1441.

12. Engbaek J, Bartholdy J, Hjortso NC. Return hospital visits and morbidity within 60 days after day surgery: a retrospective study of 18,736 day surgical procedures. Acta Anaesthesiol Scand. 2006;50(8): 911-919.

13. Keyes GR, Singer R, Iverson RE, et al. Analysis of outpatient surgery center safety using an internet-based quality improvement and peer review program. Plast Reconstr Surg. 2004;113(6):1760-1770.

14. Lermitte J, Chung F. Patient selection in ambulatory surgery. Curr Opin Anaesthesiol. 2005;18(6):598-602.

15. Gupta A. Preoperative screening and risk assessment in the ambulatory surgery patient. Curr Opin Anaesthesiol. 2009;22:705-711.

16. Khan M. Unantcipated hospital admission after ambulatory surgery. J Pak Med Assoc. 2005;55:251-252.

17. Whippey A, Kostandoff G, Paul J, Ma J, Thabane L, Ma HK. Predictors of unanticipated admission following ambulatory surgery: a retrospective case-control study. Can J Anaesth. 2013;60(7): 675-683.

18. Fleisher LA, Pasternak LR, Lyles A. A novel index of elevated risk of inpatient hospital admission immediately following outpatient surgery. Arch Surg. 2007;142(3):263-268.

19. Majholm B, Engbaek J, Bartholdy J, et al. Is day surgery safe? A Danish multicentre study of morbidity after 57,709 day surgery procedures. Acta Anaesthesiol Scand. 2012;56(3):323-331.

20. White PF. Role of rapid short-acting anesthetics, analgesics and muscle relaxants in ambulatory anesthesia. Acta Anaesthesiol Scand Suppl. 1997;111:223-226.

21. Friedman Z, Chung F, Wong DT; Canadian Anesthesiologists Society. Ambulatory surgery adult patient selection criteria - a survey of Canadian anesthesiologists. Can J Anaesth. 2004;51(5):437-443. 
22. Chung F, Mezei G, Tong D. Pre-existing medical conditions as predictors of adverse events in day-case surgery. Br J Anaesth. 1999;83(2): 262-270.

23. Stierer T, Fleisher LA. Challenging patients in an ambulatory setting. Anesthesiol Clin North America. 2003;21(2):243-261, viii.

24. Bryson GL, Chung F, Finegan BA, et al. Patient selection in ambulatory anesthesia - an evidence-based review: part I. Can J Anaesth. 2004; 51(8):768-781.

25. Bryson GL, Chung F, Cox RG, et al. Patient selection in ambulatory anesthesia - an evidence-based review: part II. Can J Anaesth. 2004; 51(8):782-794.

26. Fleisher LA, Pasternak LR, Herbert R, Anderson GF. Inpatient hospital admission and death after outpatient surgery in elderly patients: importance of patient and system characteristics and location of care. Arch Surg. 2004;139(1):67-72.

27. Devereaux PJ, Goldman L, Cook DJ, Gilbert K, Leslie K, Guyatt GH. Perioperative cardiac events in patients undergoing noncardiac surgery: a review of the magnitude of the problem, the pathophysiology of the events and methods to estimate and communicate risk. CMAJ. 2005;173(6):627-634.

28. Akhtar S. Ischemic heart disease. In: Hines RL, Marschall KE, editors. Stoelting's Anesthesia and Co-Existing Disease. 6th ed. Philadelphia, PA: Elsevier Saunders; 2012:12-67.

29. Wallace M, Haddadin AS. Systemic and pulmonary arterial hypertension. In: Hines RL, Marschall KE, editors. Stoelting's Anesthesia and Coexisting Disease. Philadelphia, PA: Churchill Livingstone/Elsevier, Inc; 2008:87-102.

30. Weksler N, Klein M, Szendro G, et al. The dilemma of immediate preoperative hypertension: to treat and operate, or to postpone surgery? J Clin Anesth. 2003;15(3):179-183.

31. Matei VA, Haddadin AS. Systemic and pulmonary arterial hypertension. In: Hines RL, Marschall KE, editors. Stoelting's Anesthesia and Co-Existing Disease. Philadelphia, PA: Elsevier Saunders; 2012: 104-119.

32. Smith I, Jackson I. Beta-blockers, calcium channel blockers, angiotensin converting enzyme inhibitors and angiotensin receptor blockers: should they be stopped or not before ambulatory anaesthesia? Curr Opin Anaesthesiol. 2010;23(6):687-690.

33. Brabant SM, Eyraud D, Bertrand M, Coriat P. Refractory hypotension after induction of anesthesia in a patient chronically treated with angiotensin receptor antagonists. Anesth Analg. 1999;89(4):887-888.

34. Licker M, Schweizer A, Hohn L, Farinelli C, Morel DR. Cardiovascular responses to anesthetic induction in patients chronically treated with angiotensin-converting enzyme inhibitors. Can J Anaesth. 2000; 47(5):433-440.

35. Bertrand M, Godet G, Meersschaert K, Brun L, Salcedo E, Coriat P. Should the angiotensin II antagonists be discontinued before surgery? Anesth Analg. 2001;92(1):26-30.

36. Aronson S. Perioperative hypertensive emergencies. Curr Hypertens Rep. 2014;16(7):448.

37. Bedford RF, Feinstein B. Hospital admission blood pressure: a predictor for hypertension following endotracheal intubation. Anesth Analg. 1980;59:367-370.

38. McLaughlin VV, Archer SL, Badesch DB, et al. ACCF/AHA 2009 expert consensus document on pulmonary hypertension a report of the American College of Cardiology Foundation Task Force on Expert Consensus Documents and the American Heart Association developed in collaboration with the American College of Chest Physicians; American Thoracic Society, Inc.; and the Pulmonary Hypertension Association. J Am Coll Cardiol. 2009;53(17):1573-1619.

39. Barst RJ, Gibbs JS, Ghofrani HA, et al. Updated evidence-based treatment algorithm in pulmonary arterial hypertension. J Am Coll Cardiol. 2009;54(1 Suppl):S78-S84.

40. Ramakrishna G, Sprung J, Ravi BS, Chandrasekaran K, McGoon MD. Impact of pulmonary hypertension on the outcomes of noncardiac surgery: predictors of perioperative morbidity and mortality. J Am Coll Cardiol. 2005;45(10):1691-1699.
41. Gibbons RJ, Abrams J, Chatterjee K, et al. ACC/AHA 2002 guideline update for the management of patients with chronic stable angina summary article: a report of the American College of Cardiology/ American Heart Association Task Force on practice guidelines (Committee on the Management of Patients With Chronic Stable Angina). J Am Coll Cardiol. 2003;41(1):159-168.

42. Poldermans D, Bax JJ, Boersma E, et al. Task Force for Preoperative Cardiac Risk, Assessment Perioperative Cardiac Management in Non-cardiac Surgery European Society of Cardiology: guidelines for pre-operative cardiac risk assessment and perioperative cardiac management in non-cardiac surgery. Eur Heart J. 2009;30(22): 2769-2812.

43. Opi L, Poole-Wilson P. Beta-blocking agents. In: Opie LH, Gersh BJ, editors. Drugs for the Heart. Philadelphia, PA: Saunders; 2009.

44. Kushner FG, Hand M, Smith SC Jr, et al. 2009 Focused Updates: ACC/AHA guidelines for the management of patients with st-elevation myocardial infarction (updating the 2004 guideline and 2007 focused update) and acc/aha/scai guidelines on percutaneous coronary intervention (updating the 2005 guideline and 2007 focused update): a report of the American College of Cardiology Foundation/American Heart Association Task Force on Practice Guidelines. Circulation. 2009;120(22):2271-2306.

45. White CM, Talati R, Phung OJ, et al. Benefits and risks associated with beta-blocker prophylaxis in noncardiac surgery. Am J Health Syst Pharm. 2010;67(7):523-530.

46. Fleisher LA, Beckman JA, Brown KA, et al. 2009 ACCF/AHA focused update on perioperative beta blockade incorporated into the ACC/AHA 2007 guidelines on perioperative cardiovascular evaluation and care for noncardiac surgery: a report of the American college of cardiology foundation/American heart association task force on practice guidelines. Circulation. 2009;120(21):e169-e276.

47. Anderson JL, Adams CD, Antman EM, et al. 2011 ACCF/AHA focused update incorporated into the acc/aha 2007 guidelines for the management of patients with unstable angina/non-ST-elevation myocardial infarction: a report of the American College of Cardiology Foundation/American Heart Association Task Force on Practice Guidelines. Circulation. 2011;123(18):e426-e579.

48. Lee AF. Implications of preoperative heart failure: the next frontier in perioperative medicine? Anesthesiology. 2008;108:551-552.

49. Hammill BG, Curtis LH, Bennett-Guerrero E, et al. Impact of heart failure on patients undergoing major noncardiac surgery. Anesthesiology. 2008;108(4):559-567.

50. Goldman L, Caldera DL, Nussbaum SR, et al. Multifactorial index of cardiac risk in noncardiac surgical procedures. NEngl J Med. 1977;297: 845-850.

51. Vega KJ, Pina I, Krevsky B. Heart transplantation is associated with an increased risk for pancreaticobiliary disease. Ann Intern Med. 1996;124(11):980-983.

52. Barash P, Akhtar S. Coronary stents: factors contributing to perioperative major adverse cardiovascular events. Br J Anaesth. 2010; 105(Suppl 1):i3-i15.

53. Servin FS. Is it time to re-evaluate the routines about stopping/keeping platelet inhibitors in conjunction to ambulatory surgery? Curr Opin Anaesthesiol. 2010;23(6):691-696.

54. Wong DH, Weber EC, Schell MJ, Wong AB, Anderson CT, Barker SJ. Factors associated with postoperative pulmonary complications in patients with severe chronic obstructive pulmonary disease. Anesth Analg. 1995;80(2):276-284.

55. Warner DO, Warner MA, Barnes RD, et al. Perioperative respiratory complications in patients with asthma. Anesthesiology. 1996;85(3): 460-467.

56. Arozullah AM, Khuri SF, Henderson WG, Daley J. Development and validation of a mutifactorial risk index for predicting pneumonia after major noncardiac surgery. Ann Intern Med. 2001;135:847-857.

57. Edrich T, Sadovnikoff N. Anesthesia for patients with severe chronic obstructive pulmonary disease. Curr Opin Anaesthesiol. 2010;23(1): $18-24$. 
58. Yamakage M, Iwasaki S, Namiki A. Guideline-oriented perioperative management of patients with bronchial asthma and chronic obstructive pulmonary disease. J Anesth. 2008;22(4):412-428.

59. Wu AC, Li L, Fung V, et al. Use of leukotriene receptor antagonists are associated with a similar risk of asthma exacerbations as inhaled corticosteroids. J Allergy Clin Immunol Pract. 2014;2(5):607-613.

60. Groeben H, Mitzner W, Brown RH. Effects of the alpha2adrenoceptor agonist dexmedetomidine on bronchoconstriction in dogs. Anesthesiology. 2004;100(2):359-363.

61. Mitchell CK, Smoger SH, Pfeifer MP, et al. Multivariate analysis of factors associated with postoperative pulmonary complications following general elective surgery. Arch Surg. 1998;133(2):194-198.

62. Thomsen T, Tonnesen H, Moller AM. Effect of preoperative smoking cessation interventions on postoperative complications and smoking cessation. Br J Surg. 2009;96(5):451-461.

63. Lindstrom D, Sadr Azodi O, Wladis A, et al. Effects of a perioperative smoking cessation intervention on postoperative complications: a randomized trial. Ann Surg. 2008;248(5):739-745.

64. Shi Y, Warner DO. Surgery as a teachable moment for smoking cessation. Anesthesiology. 2010;112(1):102-107.

65. Silvanus MT, Groeben H, Peters J. Corticosteroids and inhaled salbutamol in patients with reversible airway obstruction markedly decrease the incidence of bronchospasm after tracheal intubation. Anesthesiology. 2004;100(5):1052-1057.

66. Pien LC, Grammer LC, Patterson R. Minimal complications in a surgical population with severe asthma receiving prophylactic corticosteroids. J Allergy Clin Immunol. 1988;82(4):696-700.

67. Su FW, Beckman DB, Yarnold PA, Grammer LC. Low incidence of complications in asthmatic patients treated with preoperative corticosteroids. Allergy Asthma Proc. 2004;25(5):327-333.

68. Horne G, Devane P, Davidson A, Adams K, Purdie G. The influence of steroid injections on the incidence of infection following total knee arthroplasty. $N Z$ Med J. 2008;121(1268):U2896.

69. Lin HT, Ting PC, Chang WY, Yang MW, Chang CJ, Chou AH. Predictive risk index and prognosis of postoperative reintubation after planned extubation during general anesthesia: a single-center retrospective case-controlled study in Taiwan from 2005 to 2009. Acta Anaesthesiol Taiwan. 2013;51(1):3-9.

70. Teh SH, Nagorney DM, Stevens SR, et al. Risk factors for mortality after surgery in patients with cirrhosis. Gastroenterology. 2007;132(4): 1261-1269.

71. White PF, White LM, Monk T, et al. Perioperative care for the older outpatient undergoing ambulatory surgery. Anesth Analg. 2012;114(6): 1190-1215.

72. Kheterpal S, Tremper KK, Heung M, et al. Development and validation of an acute kidney injury risk index for patients undergoing general surgery: results from a national data set. Anesthesiology. 2009;110(3): 505-515.

73. Jarnberg PO. Renal protection strategies in the perioperative period. Best Pract Res Clin Anaesthesiol. 2004;18(4):645-660.

74. Cockroft DW, Gault MH. Prediction of creatinine clearance from serum creatinine. Nephron. 1976;16(30):1641.

75. Aldam P, Levy N, Hall GM. Perioperative management of diabetic patients: new controversies. Br J Anaesth. 2014;113(6):906-909.

76. American Diabetes Association. Statistics about Diabetes, Data from National Diabetes Statistics Report, 2014. Alexandria, VA: American Diabetes Association; 2014. Available from: http://www.diabetes.org/ diabetes-basics/statistics/\#sthash.UJFSRc0i.dpuf. Accessed May 13, 2015.

77. Sampson MJ, Dozio N, Ferguson B, Dhatariya K. Total and excess bed occupancy by age, specialty and insulin use for nearly one million diabetes patients discharged from all English acute hospitals. Diabetes Res Clin pract. 2007;77(1):92-98.

78. Lee TH, Marcantonio ER, Mangione CM, et al. Derivation and prospective validation of a simple index for prediction of cardiac risk of major noncardiac surgery. Circulation. 1999;100(10):1043-1049.
79. Frisch A, Chandra P, Smiley D, et al. Prevalence and clinical outcome of hyperglycemia in the perioperative period in noncardiac surgery. Diabetes Care. 2010;33(8):1783-1788.

80. Kwon S, Thompson R, Dellinger P, Yanez D, Farrohki E, Flum D. Importance of perioperative glycemic control in general surgery: a report from the Surgical Care and Outcomes Assessment Program. Ann Surg. 2013;257(1):8-14.

81. National Health Service Diabetes U. Management of adults with diabetes undergoing surgery and elective procedures: improving standards. http:// www.diabetologists-abcd.org.uk/JBDS/JBDS_IP_Surgery_Adults_ Full.pdf.

82. Joshi GP, Chung F, Vann MA, et al. Society for Ambulatory Anesthesia consensus statement on perioperative blood glucose management in diabetic patients undergoing ambulatory surgery. Anesth Analg. 2010;111(6):1378-1387.

83. Robertshaw HJ, McAnulty GR, Hall GH. Strategies for managing the diabetic patient. Best Pract Res Clin Anaesthesiol. 2004;18(4): 631-643.

84. Ata A, Lee J, Bestle SL, Desemone J, Stain SC. Postoperative hyperglycemia and surgical site infection in general surgery patients. Arch Surg. 2010;145(9):858-864.

85. Dhatariya K II. Does dexamethasone-induced hyperglycaemia contribute to postoperative morbidity and mortality? Br J Anaesth. 2013;110(5):674-675.

86. Simpson AK, Levy N, Hall GM. Peri-operative iv fluids in diabetic patients - don't forget the salt. Anaesthesia. 2008;63(10):1043-1045.

87. Moghissi ES, Korytkowski MT, DiNardo M, et al. American Association of Clinical Endocrinologists and American Diabetes Association consensus statement on inpatient glycemic control. Endocr Pract. 2009;15(4):353-369.

88. Langouche L, Vanhorebeek I, Vlasselaers D, et al. Intensive insulin therapy protects the endothelium of critically ill patients. J Clin Invest. 2005; 115(8):2277-2286.

89. Halkos ME, Puskas JD, Lattouf OM, et al. Elevated preoperative hemoglobin $\mathrm{A}_{1 \mathrm{c}}$ level is predictive of adverse events after coronary artery bypass surgery. J Thorac Cardiovasc Surg. 2008;136(3): 631-640.

90. O’Sullivan CJ, Hynes N, Mahendran B, et al. Haemoglobin $\mathrm{A}_{1 \mathrm{c}}\left(\mathrm{HbA}_{1 \mathrm{c}}\right)$ in non-diabetic and diabetic vascular patients. Is $\mathrm{HbA}_{1 \mathrm{c}}$ an independent risk factor and predictor of adverse outcome? Eur JVasc Endovasc Surg. 2006;32(2):188-197.

91. Gustafsson UO, Thorell A, Soop M, Ljungqvist O, Nygren J. Haemoglobin $\mathrm{A}_{1 \mathrm{c}}$ as a predictor of postoperative hyperglycaemia and complications after major colorectal surgery. Br J Surg. 2009;96(11): 1358-1364.

92. Marchant MH Jr, Viens NA, Cook C, Vail TP, Bolognesi MP. The impact of glycemic control and diabetes mellitus on perioperative outcomes after total joint arthroplasty. J Bone Joint Surg Am. 2009;91(7): 1621-1629.

93. Walid MS, Newman BF, Yelverton JC, Nutter JP, Ajjan M, Robinson JS Jr. Prevalence of previously unknown elevation of glycosylated hemoglobin in spine surgery patients and impact on length of stay and total cost. J Hosp Med. 2010;5(1):E10-E14.

94. John WG; UK Department of Health Advisory Committee on Diabetes. Use of $\mathrm{HbA}_{1 \mathrm{c}}$ in the diagnosis of diabetes mellitus in the UK. The implementation of World Health Organization guidance 2011. Diabet Med. 2012;29(11):1350-1357.

95. Rosenblatt SI, Dukatz T, Jahn R, et al. Insulin glargine dosing before next-day surgery: comparing three strategies. J Clin Anesth. 2012;24(8): 610-617.

96. Sabers C, Plevak DJ, Schroeder DR, Warner DO. The diagnosis of obstructive sleep apnea as a risk factor for unanticipated admissions in outpatient surgery. Anesth Analg. 2003;96(5):1328-1335, table of contents.

97. Gross JB, Bachenberg KL, Benumof JL, et al. Practice guidelines for the perioperative management of patients with obstructive sleep apnea: a report by the American Society of Anesthesiologists Task Force on perioperative management of patients with obstructive sleep apnea. Anesthesiology. 2006;104(5):1081-1093; quiz 1117-1118. 
98. Stierer TL, Wright C, George A, Thompson RE, Wu CL, Collop N. Risk assessment of obstructive sleep apnea in a population of patients undergoing ambulatory surgery. J Clin Sleep Med. 2010;6(5): 467-472.

99. Joshi GP, Ankichetty SP, Gan TJ, Chung F. Society for Ambulatory Anesthesia consensus statement on preoperative selection of adult patients with obstructive sleep apnea scheduled for ambulatory surgery. Anesth Analg. 2012;115(5):1060-1068.

100. Rosero EB, Joshi GP. Nationwide use and outcomes of ambulatory surgery in morbidly obese patients in the United States. J Clin Anesth. 2014;26(3):191-198.

101. Khalid U, Ather S, Bavishi C, et al. Pre-morbid body mass index and mortality after incident heart failure: the ARIC Study. J Am Coll Cardiol. 2014;64(25):2743-2749.

102. Punjabi NM. The epidemiology of adult obstructive sleep apnea. Proc Am Thorac Soc. 2008;5(2):136-143.

103. Gupta RM, Parvizi J, Hanssen AD, Gay PC. Postoperative complications in patients with obstructive sleep apnea syndrome undergoing hip or knee replacement: a case-control study. Mayo Clin Proc. 2001 76(9):897-905
104. American Academy of Sleep Medicine Task Force Sleep-related breathing disorders in adults: recommendations for syndrome definition and measurement techniques in clinical research. The Report of the American Academy of Sleep Medicine Task Force. Sleep. 1999;22:667.

105. Lofsky A. Sleep apnoea and narcotic postoperative pain medication: a morbidity and mortality risk. Anaesth Patient Saf Found Newsl. 2002;17:24-25.

106. Culle DJ. Obstructive sleep apnoea and postoperative analgesia a potentially dangerous combination. J Clin Anesth. 2001;13: 83-85.

107. Seet E, Chung F. Obstructive sleep apnea: preoperative assessment. Anesthesiol Clin. 2010;28(2):199-215.
Ambulatory Anesthesia

\section{Publish your work in this journal}

Ambulatory Anesthesia is an international, peer reviewed, open access journal publishing articles that address all aspects of ambulatory anesthesia practice, in particular: anesthetic techniques, sedation and safety practices, pharmacokinetics, preoperative evaluation, analgesia interventions, regulatory and compliance issues, postoperative recovery,

Submit your manuscript here: http://www.dovepress.com/ambulatory-anesthesia-journal

\section{Dovepress}

patient satisfaction, administrative topics, and cost analysis themes. The manuscript management system is completely online and includes a very quick and fair peer review system, which is all easy to use. Visit http://www.dovepress.com/testimonials.php to read real quotes from published authors. 